\title{
Blockade of complement activation product C5a activity using specific antibody attenuates intestinal damage in trinitrobenzene sulfonic acid induced model of colitis
}

\author{
Guojiang Chen ${ }^{1,6}$, Yuemei Yang ${ }^{1,2,6}$, Xudong Gao ${ }^{2,6}$, Yan Dou ${ }^{3}$, Huihui Wang ${ }^{1,4}$, Gencheng Han ${ }^{1}$, Renxi Wang ${ }^{1}$, \\ Jianan Wang ${ }^{1}$, Liyan Wang ${ }^{1}$, Xinying $\mathrm{Li}^{1}$, Renfeng Guo ${ }^{5}$, He Xiao ${ }^{1}$, Beifen Shen ${ }^{1}$ and Yan $\mathrm{Li}^{1}$
}

Complement represents a chief component of innate immunity in host defense. However, excessive complement activation has been involved in the pathogenesis of inflammatory diseases. In this study, we investigated the contribution of complement to intestinal pathology of patients and rodents with inflammatory bowel disease. The expression of complement effectors (C3a and C3) was increased remarkably in inflamed colons of IBD patients compared with those of normal counterparts. In accordance with this, the sustained activation of complement in serum and colon (including elevated C3a and C5a levels, enhanced hemolytic activity, downregulated expression of C5a receptors) was observed, following the establishment of 2,4,6-trinitrobenzene sulfonic acid (TNBS)-induced colitis, which peaked at $24 \mathrm{~h}$. Mice pretreated with neutralizing anti-C5a antibodies $(-2,0$, and 2 days after TNBS instillation) had significantly reduced weight loss and improved macroscopic/microscopic scores, comparable to the efficacy of prednisolone treatment. Strikingly, treatment with anti-C5a at $24 \mathrm{~h}$ after TNBS instillation showed remarkable therapeutic effects, whereas prednisolone did not. The efficacy of anti-C5a administration was associated with decreased release of proinflammatory chemokines and cytokines, inhibition of infiltration of neutrophils into colons, and enhanced Th2 response. These findings suggest a disease-promoting role of complement, particular $\mathrm{C} 5 \mathrm{a}$, in the pathology of TNBS-induced colitis in mice, indicating possible therapeutic potentials for C5a-specific antibody in IBD.

Laboratory Investigation (2011) 91, 472-483; doi:10.1038/labinvest.2010.183; published online 22 November 2010

KEYWORDS: antibody-based therapy; complement C5a; neutrophil; Th2 response; TNBS colitis

The inflammatory bowel diseases (IBDs) encompassing Crohn's disease (CD) and ulcerative colitis (UC) are chronic inflammatory disorders of gastrointestinal tract, characterized by dysfunction of mucosal $\mathrm{T}$ cells, abnormal cytokine production, cellular inflammation, and ultimately damage to the intestinal lining. ${ }^{1}$ Although the etiology of IBD remains unknown, there is circumstantial evidence to link IBD to the mucosal immune system's failure to attenuate immunity to endogenous antigen. ${ }^{1}$ In recent years, several animal IBD models have been developed. ${ }^{2,3}$ Although the relationship of many of these models to human disease is imperfect, the hapten-induced model of colonic inflammation in which 2,4,6-trinitrobenzene sulfonic acid (TNBS) is delivered intrarectally to $\mathrm{BALB} / \mathrm{c}$ mice displays human $\mathrm{CD}$-like features, notably predominantly IL-12-driving Th1 activity of the mucosal $\mathrm{CD}^{+}{ }^{+} \mathrm{T}$-cell population and transmural mononuclear inflammation. ${ }^{3}$ More recently, a pathogenic role of IL-23, the cytokine sharing $\mathrm{p} 40$ subunits with IL-12, has been evidenced in the development of CD. ${ }^{4}$ Deficiency of IL-23specific subunits (p19) leads to failure of colitis induction in a T-cell transfer model. This effect is attributed to suppression of IL-17 production and Th17 differentiation in the colons. ${ }^{5}$ The factors that initiate intestinal pathology of $\mathrm{CD}$ and elicit Th1/Th17 immune reaction, however, are still

\footnotetext{
${ }^{1}$ Department of Molecular Immunology, Institute of Basic Medical Sciences, Beijing, People's Republic of China; ${ }^{2}$ Department of Molecular and Cellular Pharmacology, College of Pharmaceutical Science and Technology, Tianjin University, Tianjing, People's Republic of China; ${ }^{3}$ Department of Gastroenterology, General Hospital of PLA, Beijing, People's Republic of China; ${ }^{4}$ Center of Molecular Biology, Inner Mongolia Medical College, Hohhot, People's Republic of China and ${ }^{5}$ InflaRx GmbH, Jena, Germany

Correspondence: Professor Y Li, Department of Molecular Immunology, Institute of Basic Medical Sciences, Taiping Road, Number 27, Beijing 100850, People's Republic of China.

E-mail: liyan62033@yahoo.com.cn

${ }^{6}$ These authors contributed equally to this work.

Received 9 June 2010; revised 26 September 2010; accepted 27 September 2010
} 
elusive. Uncontrolled innate immune response to microflora is thought to be important for the initiation of intestinal inflammation. ${ }^{6,7}$ As a component of innate immunity, alteration of several toll-like receptor (TLR) expression has been found in $\mathrm{IBD}^{8}$ and specific mutations of the NOD2 (a family of intracellular bacterial sensors) gene have been definitely associated with increased susceptibility to $\mathrm{CD}{ }^{9}$

Complement is another arm of innate immune system having a role in host defenses against invading pathogens and in clearance of potentially damaging cell debris. It consists of more than 30 plasma proteins and glycoproteins, as well as soluble or membrane-bound receptors. Activation of the complement system leads to generation of complement protein split products, especially anaphylatoxins C3a and C5a. ${ }^{10}$ Although having a defensive role in physiological conditions, these components have recently been implicated in the pathogenesis of many inflammatory and immunological diseases. ${ }^{11-16}$ These activation products are not necessarily the initiating factors in the inflammatory disorders, they appear to be responsible for promoting and perpetuating inflammatory reactions. Among the complement activation products, $\mathrm{C} 5 \mathrm{a}$ is one of the most potent inflammatory peptides, with a broad spectrum of functions. C5a is a strong chemoattractant for neutrophils and also has chemotactic activity for monocytes and macrophages. ${ }^{17}$ Recently, C5a has been shown to be involved in modulation of cytokine expression from various cell types. ${ }^{18,19}$ C5a exerts its effects through the high-affinity receptors, mainly CD88 (C5aR). C5aR expression was not only described on myeloid cells, including neutrophils and macrophages, but also found on a variety of nonmyeloid cells in many organs, ${ }^{20-22}$ which suggests the implication of $\mathrm{C} 5 \mathrm{a} / \mathrm{C} 5 \mathrm{aR}$ signaling in the pathogenesis of organ-specific inflammation.

The representation of components of the complement system is limited under normal conditions in the gastrointestinal tract. Both direct and indirect effects of complement activation have been implicated as having roles in tissue injury associated with inflammatory diseases of gastrointestinal tract. ${ }^{23,24}$ However, the contribution of complement activation products, especially C5a, to pathology of colitis remains largely unknown. In this study, complement activation in IBD patients and colitic mice was detected and the role of complement activation products C5a in IBD pathogenesis was investigated using neutralizing antibody to C5a. We found intensive and sustained activation of complement in periphery and local tissues of IBD patients and colitic mice. Blockade of C5a using a specific antibody have preventive and therapeutic effects on TNBS-induced colitis, which was associated with recovery of immune homeostasis in the colons after anti-C5a treatment.

\section{MATERIALS AND METHODS}

\section{Collection of Human Tissues}

Normal intestinal mucosa was obtained from macroscopically and microscopically unaffected areas of patients with colon cancer. Intestinal mucosa was also obtained from surgically resected specimens from patients with UC or CD, diagnosed on the basis of clinical, radiographic, endoscopic, and histological findings according to established criteria. All experiments were performed strictly according to the institutional guidelines of General Hospital of PLA with prior informed consent of the patients. These procedures and animal experiments were also approved by the ethical committee of Institute of Basic Medical Sciences.

\section{Mice and Induction of Colitis}

Inbred male BALB/c mice aged 6-8 weeks were housed under standard conditions and supplied with drinking water and food ad libitum. Colitis was induced by rectal administration of $3 \mathrm{mg}$ of 2,4,6-trinitrobenzene sulfonic acid (TNBS; Sigma Chemical, St Louis, MO, USA) in 50\% ethanol, using a vinyl catheter positioned $3.5 \mathrm{~cm}$ proximal to the anus. During the procedure, mice were anaesthetized using ether. After instillation, animals were kept vertically for $30 \mathrm{~s}$. Control mice underwent identical procedures, but were instilled with ethanol $50 \%$ dissolved in phosphate-buffered saline (PBS). In some experiments, as previously described, ${ }^{25,26}$ mice were sensitized with $3 \mathrm{mg}$ TNBS in 50\% ethanol by skin painting on day 1 . On day 8 , TNBS at the same dose was administrated intrarectally. All studies were performed under the approval of the Institute's Ethics Committee and are in agreement with the guidelines for the proper use of animals in biomedical research. At the end of the experiments, mice were killed by cervical dislocation under anesthesia.

\section{Preparation of Polyclonal Anti-Mouse C5a Antibody}

Rabbit polyclonal antibodies against mouse C5a were prepared as described previously in our study. ${ }^{27}$ In brief, carboxyl-terminal peptide CTIANKIRKESPHKPVQLGR was selected for development of KLH conjugates and immunization of rabbits. After several immunizations, the antibodies were affinity-purified from serum. Their specificity to C5a was identified by immunosorbent assays (Supplementary Figure 1A). The biological activity of polyclonal antibody, for example, blocking upregulation of CD11b expression by leukocytes after C5a stimulation (Supplementary Figure 1B) and inhibition of enhanced KC expression (Supplementary Figure 1C) by leukocytes after synergistic stimulation with LPS and C5a were also confirmed.

\section{Anti-C5a Antibody Treatment}

Mice were treated with polyclonal anti-mouse C5a antibodies or rabbit IgG intraperitoneally $-2,0,2$ days after rectal challenge at the dose of $400 \mu \mathrm{g} /$ mouse, respectively. To assess the therapeutic effects, in some experiments anti-C5a antibody was administrated 1 and 3 days after TNBS challenge at the same dose of 400 or $20 \mu \mathrm{g} /$ mouse, respectively. In addition, as positive controls, prednisolone was administrated intraperitoneally at the dose of $1 \mathrm{mg} / \mathrm{kg}$ on the same intervals. 


\section{Colon Homogenates}

A $1 \mathrm{~cm}$ segment was divided from the distal $4 \mathrm{~cm}$ of the harvest colon. Wet weight was recorded separately for the whole distal $4 \mathrm{~cm}$ and the portion taken for homogenation. Colon tissue samples were homogenized in PBS containing a cocktail of protease inhibitors ( $1 \mu \mathrm{l}$ to $20 \mathrm{mg}$ of tissue according to the manufacturer's protocol, Roche, Germany) with a Polytron homogenizer and centrifuged at $12000 \mathrm{~g}$ for $10 \mathrm{~min}$. The supernatants were stored at $-2^{\circ} \mathrm{C}$ until used for ELISA analysis.

\section{Plasma Pool and ELISA for Cytokines}

After induction of colitis, animals were killed at the indicated time points and blood was drawn from the inferior vena cava. Citrate was used as an anti-coagulant (ACD from Baxter Health Care Inc., USA). To block complement activation, FUT-175 (BD Biosciences, USA) was added into blood samples immediately. Plasma were collected and stored at $-20^{\circ} \mathrm{C}$.

Human and mouse C5a, C3a ELISA kits, mouse IFN- $\gamma$, IL-4 ELISA kits were purchased from BD Pharmingen (USA). Mouse IL-6, TNF- $\alpha$, IL-12p70, IL-1 $\beta$, MCP-1, IL-10, TGF- $\beta$, IL-17, IL-23 ELISA kits were purchased from eBioscience (USA).

\section{Hemolytic Complement Assay}

Mouse plasma, pooled at different time points after TNBS instillation, was serially diluted in TBS $(75 \mathrm{~g} / \mathrm{l} \mathrm{NaCl}, 177 \mathrm{ml} / 1$ $1 \mathrm{~N} \mathrm{HCl}, 28 \mathrm{ml} / 1$ Triethanolamine, $1.2 \mathrm{ml} / 11.25 \mathrm{M} \mathrm{CaCl}_{2}$, $1.2 \mathrm{ml} / 14.16 \mathrm{M} \mathrm{MgCl}_{2}$ ) and incubated with $0.5 \mathrm{ml}$ sensitized sheep red blood cells at $37^{\circ} \mathrm{C}$ for $60 \mathrm{~min}$. The complement reaction was stopped by adding ice-cold TBS followed by a centrifugation step $(2500 \mathrm{~g}, 5 \mathrm{~min})$. The dilution causing lysis of sheep red blood cells was determined by measuring absorbance of the supernatant (at $450 \mathrm{~nm}$ ).

\section{Lymphocyte and Lamina Propria Mononuclear Cell Preparation}

At 4 days after TNBS instillation, lymphocytes were isolated from mesenteric lymph nodes by passing them through nylon mesh and were suspended in RPMI 1640 medium, which was supplemented with $10 \%$ fetal calf serum. Lamina propria mononuclear cells (LPMCs) were isolated from lamina propria using a modified technique of Van der Heijden and Stock. ${ }^{28}$ The resultant LPMCs were plated on a plastic surface for separation into adherent and nonadherent cell populations. Nonadherent cells were further enriched by negative selection using mouse CD4-negative isolation microbeads (Miltenyi Biotec). The resultant cell populations were shown by flow cytometry to contain $>90 \% \mathrm{CD}^{+}{ }^{+} \mathrm{T}$ cells. The cells were seeded in 96-well plate in triplicate $\left(4 \times 10^{5}\right.$ cells/well $)$ with the cocktail of anti-CD3 $(1 \mu \mathrm{g} / \mathrm{ml} ; e$ Bioscience) and anti-CD28 $(2 \mu \mathrm{g} / \mathrm{ml} ; e$ Bioscience). At $72 \mathrm{~h}$ after incubation, the supernatants were collected for ELISA analysis.

\section{Flow Cytometry}

Antibodies used for flow cytometry analysis are as follows: FITC-labeled anti-murine IFN- $\gamma$ (XMG1.2) is purchased from Biolegend (USA). FITC-labeled anti-murine CD11b (M1/70) and PE-labeled anti-murine IL-17 (TC11-18H10.1) are purchased from BD Pharmingen. PE-labeled anti-murine CD88 (20/70) is purchased from Abcam (USA). For intracellular staining, cells were stimulated with a cocktail of $50 \mathrm{ng} / \mathrm{ml} \mathrm{PMA}, 1 \mu \mathrm{g} / \mathrm{ml}$ inomycin, and $1 \mu \mathrm{g} / \mathrm{ml}$ brefeldin A (all from Sigma) for $4 \mathrm{~h}$. Thereafter, these cells were fixed, permeabilized with Fix \& Perm cell permeabilization kit (eBiosciences), and stained with Abs specific to intracellular cytokines. For the detection of CD88 expression, whole blood was treated with fluorescence-activated cell sorting lysing solution (BD Biosciences) to eliminate red blood cells after staining. Data collection and analysis were performed on a fluorescence-activated cell sorting Calibur flow cytometry using CellQuest software (Becton Dickinson, USA).

\section{Measurement of Myeloperoxidase Activity}

Tissue myeloperoxidase (MPO) activity was determined by a standard enzymatic procedure as described previously, ${ }^{29}$ with minor modifications. Briefly, after the samples have been weighed, a tissue sample (approximately $300 \mathrm{mg}$ ) was homogenized in a buffer $(0.5 \%$ hexadecyltrimethylammonium bromide in $50 \mathrm{Mm}$ potassium phosphate buffer, $\mathrm{pH}$ 6.0) three times for $30 \mathrm{~s}$ each on ice. The sample was centrifuged at $20000 \mathrm{~g}$ for $20 \mathrm{~min}$ at $4{ }^{\circ} \mathrm{C}$ and the supernatant was collected. The supernatants $(100 \mu \mathrm{l})$ were then added to $2.9 \mathrm{ml}$ of $50 \mathrm{mM}$ phosphate buffer ( $\mathrm{pH} 6.0$ ) containing $0.167 \mathrm{mg} / \mathrm{ml}$ $O$-dianisidine hydrochloride and $0.0005 \%$ hydrogen peroxide, and absorbances were measured using a spectrometer at $25^{\circ} \mathrm{C}$. Results for colon MPO content were converted to absorbance units per gram of tissue.

\section{Histological Assessment of Tissues}

Colons removed from mice at indicated times of death were fixed in $10 \%$ neutral-buffered formalin solution and then embedded in paraffin, cut into tissue sections, and stained with hematoxylin and eosin. Stained sections were examined for evidence of colitis using as criteria: the presence of lymphocyte infiltration, elongation and/or distortion of crypts frank ulceration, and thickening of the bowel wall. The degree of inflammation on microscopic cross-sections of the colon was graded semiquantitatively from 0 to $4(0$, no evidence of inflammation; 1 , low level of lymphocyte infiltration with infiltration seen in $<10 \%$ high-power field (hpf), no structural changes observed; 2, moderate lymphocyte infiltration with infiltration seen in 10-25\% hpf, crypt elongation, bowel wall thickening that does not extend beyond mucosal layer, no evidence of ulceration; 3, high level of lymphocyte infiltration with infiltration seen in $25-50 \%$ hpf, high vascular density, thickening of bowel wall that extends beyond mucosal layer; and 4, marked degree of lymphocyte infiltration with infiltration seen in $>50 \% \mathrm{hpf}$, 
high vascular density, crypt elongation with distortion, transmural bowel wall thickening with ulceration).

\section{Immunohistochemistry for Polymorphonuclear Cell Infiltration}

Paraffin-embedded sections were processed conventionally and stained with rat anti-mouse Gr-1 mAb (1:50, eBiosciences) or anti-F4/80 (1:100, Serotec, USA) for $1 \mathrm{~h}$ at room temperature. After washing with TBS, the sections were incubated with Horseradish peroxidase (HRP)-conjugated secondary antibody (Dako, USA) for $30 \mathrm{~min}$. Diaminobenzidine $(\mathrm{DAB})$ substrate reagents were used for detecting positive cells. Counterstaining was performed for $1 \mathrm{~min}$ in hematoxylin.

\section{Quantitative Real-Time Transcription-PCR}

RNA was isolated from intestinal tissue samples preserved in RNAlater (QIAGEN, USA), using the RNAeasy Mini Kit (QIAGEN). Complementary DNAs were synthesized with a Quantitect Reverse Transcription Kit (QIAGEN) according to the manufacturer's instructions. Quantitative real-time PCR was performed using TaqMan PCR master mix (Applied Biosystems) and a VIC-labeled probe for $\beta$-actin, together with FAM-labeled probes for human $\mathrm{C} 3$, C5, mouse $\mathrm{C} 3$, and $\mathrm{C} 5$ and $\mathrm{KC}$ obtained from Assays On Demand (Applied Biosystems) in a DNA Engine Opticon 2 System (MJ Research). The relative mRNA expression level of each molecule (in arbitrary units (AU)) was calculated by dividing the expression level by the average level in control samples after normalization to the corresponding $\beta$-actin mRNA level.

\section{Data Analysis}

Statistical analyses were performed using the student's $t$-test or one-way analysis of variance. A value of $P<0.05$ was considered significant.

\section{RESULTS}

\section{Complement Activation in the Inflamed Colon Tissues of IBD Patients}

Abnormal complement activity is thought to be important in IBD pathology, ${ }^{23}$ however, there is limited evidence for this. To investigate the relationships between complement activation and intestinal inflammation, the intestinal tissue samples of UC $(n=15)$ and $\mathrm{CD}(n=10)$ patients were collected. Meanwhile, for the purpose to exactly define the contribution of complement activation to intestinal pathology, the intestinal tissues without signs of inflammation identified by macroscopic and microscopic examination (data not shown), in patients with colon cancer $(n=8)$, were used as controls. As complement-activated products C3a, C5a are key proinflammatory factors involving enormous inflammatory diseases, their contents in the colon were detected. C3a expression was significantly increased in the inflamed tissues from UC or CD patients (Figure 1a), compared with that in the controls. Furthermore, C3a production in inflamed
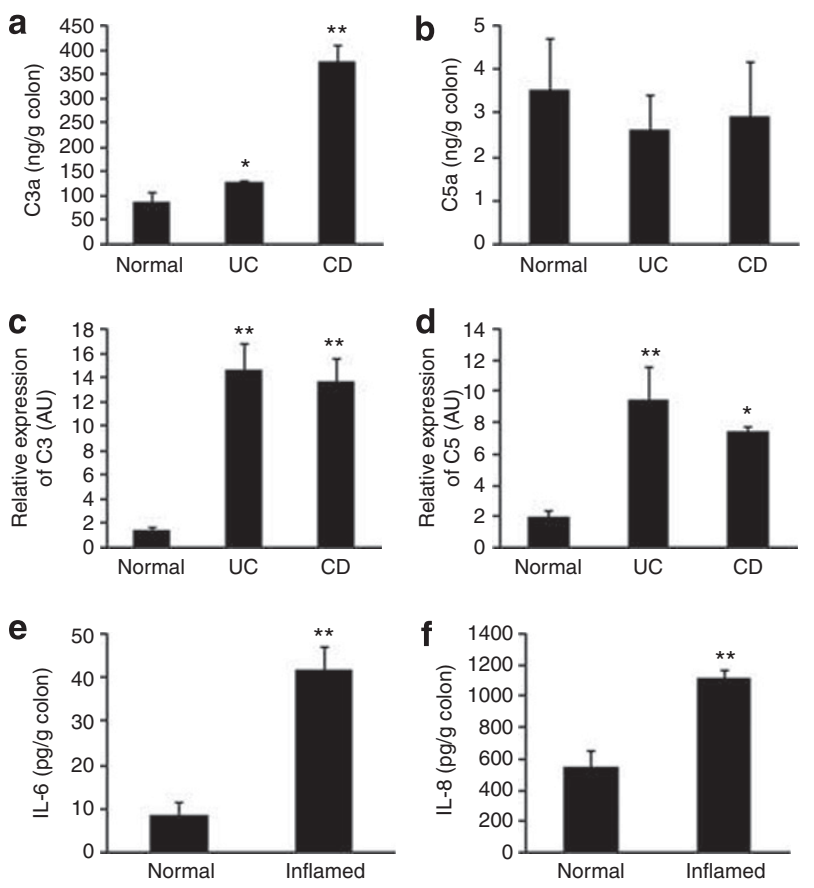

Figure 1 Complement activation in affected colons of IBD patients. Colonic biopsy samples from UC $(n=15), C D(n=10)$ patients or controls $(n=8)$ were homogenated. C3a (a) and $\mathrm{C} 5 \mathrm{a}$ (b) production were examined by ELISA. Relative mRNA expression levels of $\mathrm{C} 3(\mathbf{c})$ and $\mathrm{C} 5$ (d) in the colons of UC, CD patients or controls were quantified by real-time RT-PCR. IL-6 (e), and IL-8 (f) production in the colonic tissues of UC patients or controls was detected simultaneously. ${ }^{\star} P<0.05 ;{ }^{* * P}<0.01$.

samples of CD patients was higher than that in UC counterparts, indicating an intimate implication of complement activation in CD pathogenesis. This increase in C3a protein level appeared to result from enhanced expression of $\mathrm{C} 3$ in mRNA level (Figure 1c). Interestingly, despite no statistic difference, C5a contents in the inflamed samples from UC or $\mathrm{CD}$ patients (Figure $1 \mathrm{~b}$ ) were lower than controls. This may be because of binding of $\mathrm{C} 5 \mathrm{a}$ to its receptor $\mathrm{C} 5 \mathrm{aR}$, leading to internalization of the complex. ${ }^{30}$ To address this, C5 mRNA expression was detected. C5 mRNA levels were elevated significantly in inflamed samples of IBD patients (Figure 1d).

$\mathrm{C} 3 \mathrm{a}$ and $\mathrm{C} 5 \mathrm{a}$ are well known to serve as anaphylatoxins with their ability to regulate the expression of proinflammatory mediators such as IL- 6 and IL- $8 .^{31,32}$ Thus, the production of these cytokines in local tissues involving intestinal pathology was detected. Inflamed tissues contained much higher amounts of IL-6 (Figure 1e) and IL-8 (Figure 1f) compared with that of controls.

\section{Complement Activation in TNBS-Induced Colitis}

To further uncover the contribution of complement activation to IBD pathology, TNBS-induced colitis model was used. First, the levels of C3a and C5a in plasma at different time points after TNBS administration were examined. The results showed that C5a production increased rapidly after colitis 

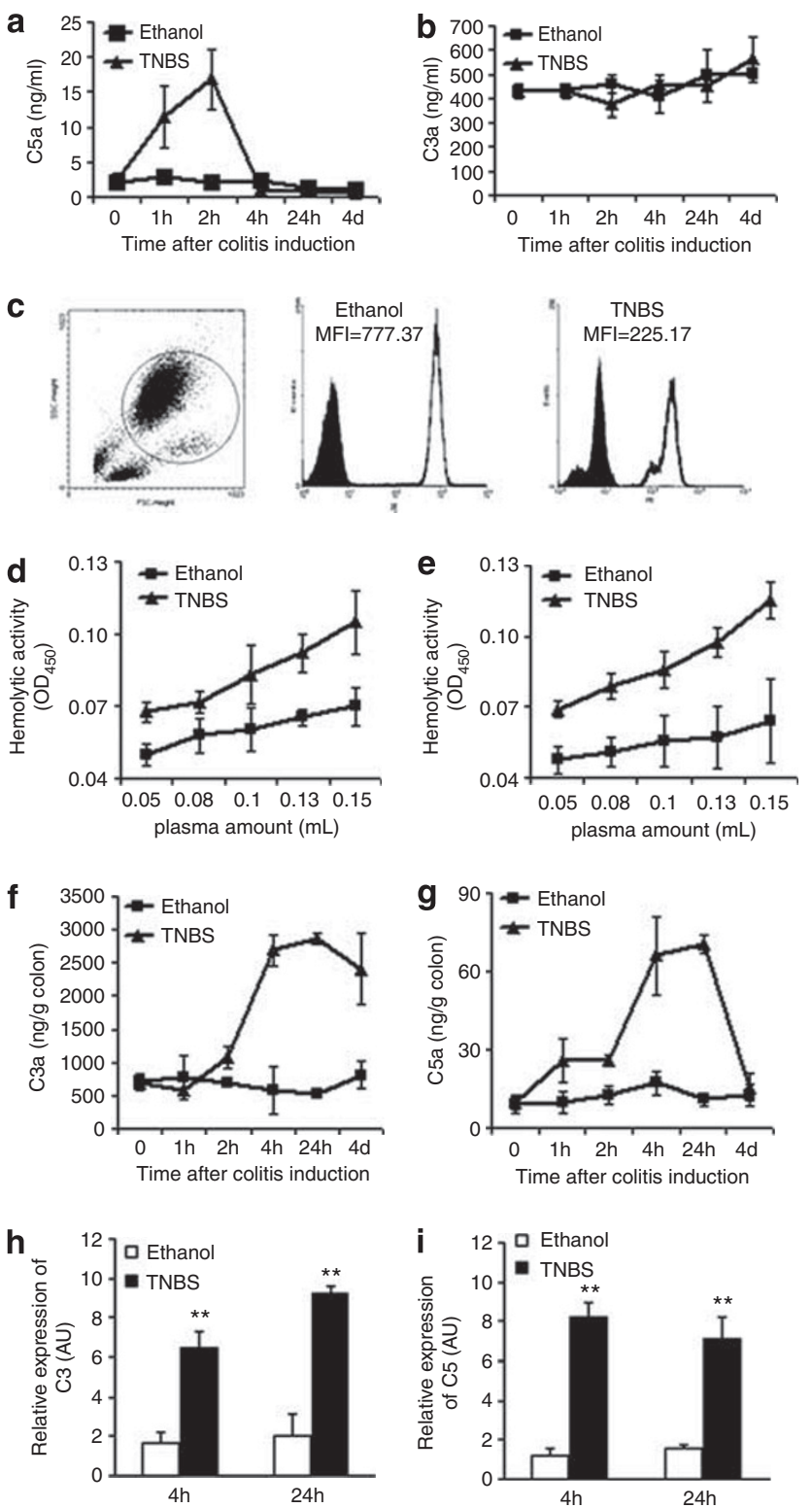

Figure 2 Complement activation in TNBS-induced colitis. At different time points following TNBS $(n=10)$ or ethanol instillation $(n=8)$, C5a $(\mathbf{a})$ and C3a (b) contents in the plasma treated with FUT-175 were detected by ELISA. At $4 \mathrm{~h}$ after TNBS instillation, blood samples from peripheral blood of ethanol or TNBS-treated mice $(n=5)$ were collected. C5aR expression on the surface of gated cells was examined by flow cytometry. Representative plots were shown (c). Hemolytic activity of plasma from ethanol $(n=3)$ or TNBS-instilled mice at $(n=6) 2$ (d) and $4 \mathrm{~h}(\mathbf{e})$ after colitis induction was detected. At indicated time points after TNBS instillation, colons were homogenated and supernatants were prepared for detection of $\mathrm{C} 3 \mathrm{a}$ (f) and C5a (g) protein levels. Each group consisted of 10-14 mice. C3 (h) and C5 (i) mRNA expression in the colons at 4 and $24 \mathrm{~h}$ following ethanol $(n=4)$ or TNBS instillation $(n=5)$ was quantified by real-time RT-PCR. ${ }^{*} P<0.01$.

induction, peaked at $2 \mathrm{~h}$ (Figure 2a). The amounts of C5a protein at this time point in plasma of TNBS-instilled mice reached eightfold compared with that in control mice. At $4 \mathrm{~h}$ after induction, plasma C5a contents decreased drastically to the level comparable to that of controls. As interaction between $\mathrm{C} 5 \mathrm{a}$ and $\mathrm{C} 5 \mathrm{aR}$ easily leads to internalization of the receptor, ${ }^{33}$ the drop of C5a level may be due to this effect. To address this, C5aR expression on the surface of peripheral blood leukocytes at the same time point was detected. The result showed that C5aR (CD88) expression on the surface of peripheral blood leukocytes was much lower than controls at this time point (Figure 2c). Furthermore, given that terminal products of complement activation, C5b-9, function as membrane-attacked complex to kill target cells,${ }^{34}$ hemolytic activity of C5b-9-containing plasma from colitic mice or controls was examined. The results of enhanced hemolytic capacity of plasma from colitic mice at 2 (Figure $2 \mathrm{~d}$ ) and $4 \mathrm{~h}$ (Figure 2e) after TNBS instillation further underscored excessive complement activation after colitis induction. Although plasma C3a levels were detected, augmented production of C3a in periphery was not observed after colitis induction (Figure 2b). Overall, these data suggest the occurrence of systemic complement activation at the early phase after colitis induction.

Next, to further define the involvement of complement activation in colitis pathology, we focus on the production of complement C5a, C3a in the intestinal tissues. Sustained and intensive activation of complement in target tissues was found by showing enhanced expression of complementactivated products after TNBS instillation, especially C3a (Figure 2f). In contrast to a rapid drop of plasma C5a contents to baselines at $4 \mathrm{~h}$, prolonged activation of complement in intestinal tissues was identified by high production of intestinal C5a, which was still seen at $24 \mathrm{~h}$ after colitis induction (Figure 2g). Intestinal complement activation was partially due to enhanced synthesis of C3 (Figure 2h) and C5 (Figure 2i).

One may consider that the quick complement activation simply reflects a basic immune reaction against TNBS rather than the fundamental mechanism of IBD, as TNBS is a wellknown immunogenic hapten. To rule out the possibility, TNBS was administrated into skin on day 1 , followed by rectal instillation on day 8. The plasma and supernatants of colon homogenates were collected at $2 \mathrm{~h}$ and 1 day after TNBS administration into skin alone or combined with rectal instillation, respectively. The results showed that, TNBS administration into skin and colon led to high levels of C5a production in the plasma at $2 \mathrm{~h}$ after TNBS, whereas TNBS administration into skin alone had no effects (Supplementary Figure 2A). In agreement with the result in Figure 2a, plasma C5a level dropped to the baseline on day 1 after combined administration of TNBS into skin and colon (Supplementary Figure 2A). Significant upregulation of C5a level in the colon was observed at $2 \mathrm{~h}$ and 1 day after combined administration of TNBS into skin and colon (Supplementary Figure 2B). These data further underscored intimate correlation of $\mathrm{C} 5 \mathrm{a}$ production with IBD pathogenesis, which may precipitate intestinal inflammatory responses and ultimately colitis manifestation. 


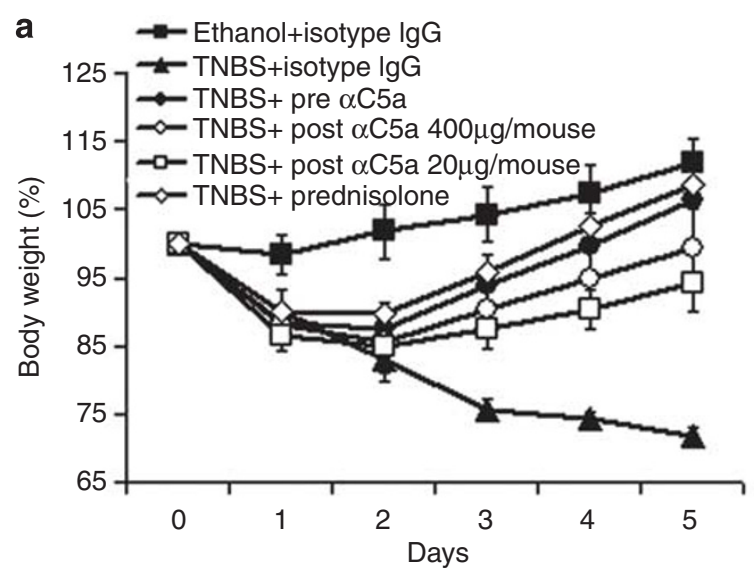

b

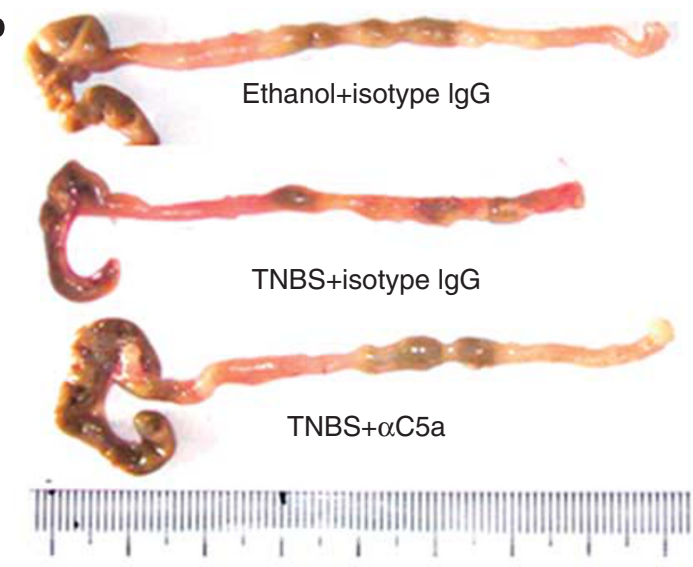

C

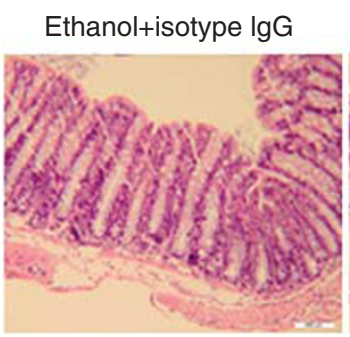

TNBS+isotype lgG

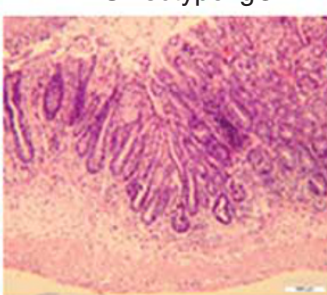

TNBS $+\alpha C 5 a$

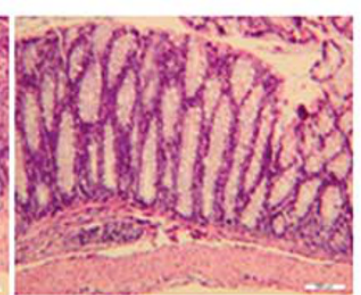

d

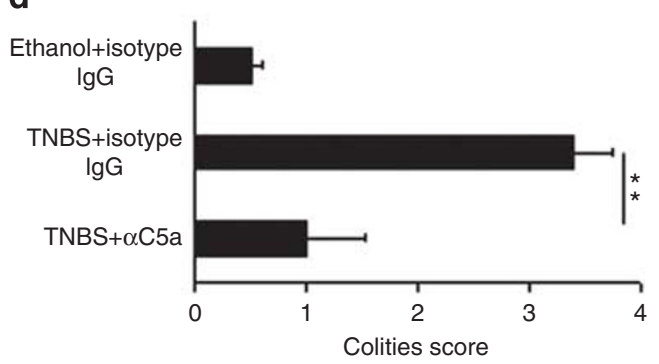

Figure 3 Anti-C5a treatment prevents and ameliorates intestinal destruction in TNBS-induced colitis. (a) Mice were treated with anti-C5a antibody, rabbit IgG or prednisolone at indicated doses intraperitoneally (i.p.) at $24 \mathrm{~h}$ before TNBS or ethanol instillation. Another group was injected i.p. with anti-C5a antibody $24 \mathrm{~h}$ after TNBS challenge. Weight as a percentage of the initial weight at day 0 was shown. Data represent the mean weight $\pm \mathrm{s}$.d. and is pooled from four independent experiments. Each group consisted of 18-35 mice. (b) Macroscopic images of the colons from anti-C5a or isotype antibody-treated mice. (c) Hematoxylin and eosin staining of the colons from anti-C5a or isotype antibody-treated mice. The graph is representative for 8-10 mice per group. (d) Colitis score from anti-C5a or isotype antibody-treated mice. The data are shown as mean \pm s.d. of 5-6 mice per group. ${ }^{* *}>0.01$.

\section{Anti-C5a Antibody Treatment has Preventive and Therapeutic Effects on TNBS-Induced Colitis}

To investigate whether blockade of C5a activity affected the course of TNBS colitis, we injected mice with polyclonal antibody to C5a before or after colitis induction. Animals that received TNBS in association with control IgG experienced severe weight loss (Figure 3a). In contrast, mice that received anti-C5a before rectal challenge had clearly less weight loss, which was comparable to that of prednisolone administration (Figure 3a). Thus, the following study chose this regimen to evaluate the effects of anti-C5a treatment on macroscopic and microscopic manifestations of TNBS colitis. Importantly, injection of anti-C5a $24 \mathrm{~h}$ after TNBS instillation, at this time of systemic and local complement activation was observed, which resulted in improvement of clinical symptoms, including rescue of weight loss (Figure 3a). Therapeutic effects of prednisolone in TNBS colitis were also addressed, however, no signs of improvement of colitis were seen (data not shown), indicating the potentials of anti-C5a in therapeutic application in clinic. Furthermore, to rule out the possibility that higher therapeutic effect of C5a antibody over prednisolone is because of higher dose used, the same dose of C5a antibody was administrated. The result showed that, at the dose of $1 \mathrm{mg} / \mathrm{kg}$ (eg, $20 \mu \mathrm{g} /$ mouse), anti-C5a also exhibited therapeutic effects (Figure $3 a$ ).

The efficacy of anti-C5a therapy was directly reflected in the levels of macroscopic injury observed in that C5a-specific antibody-treated mice did not exhibit significant shortening and thickening of the colon (Figure $3 \mathrm{~b}$ ). Consistent with these macroscopic changes, the control Ab-treated groups showed marked, transmural infiltration with inflammatory cells and injury with ulceration (Figure 3c). In contrast, mice treated with anti-C5a exhibited less severe histological features of colitis (Figure 3c). When quantified by a histological system for evidence of inflammation and injury, these histological changes were highly significant (Figure $3 \mathrm{~d}$ ). We also evaluated the histopathology of colons from colitic mice treated with anti-C5a or prednisolone. In agreement with the change of body weight, mice treated with anti-C5a had lower score of colitis, whereas treatment with prednisolone did not ameliorate severity of colitis (Supplementary Figure 3A).

\section{Anti-C5a Treatment Recovers Cytokine Homeostasis in Colonic Tissues of TNBS-Instilled Mice}

To determine whether this anti-C5a-mediated protection from colitis was associated with alterations in cytokine 

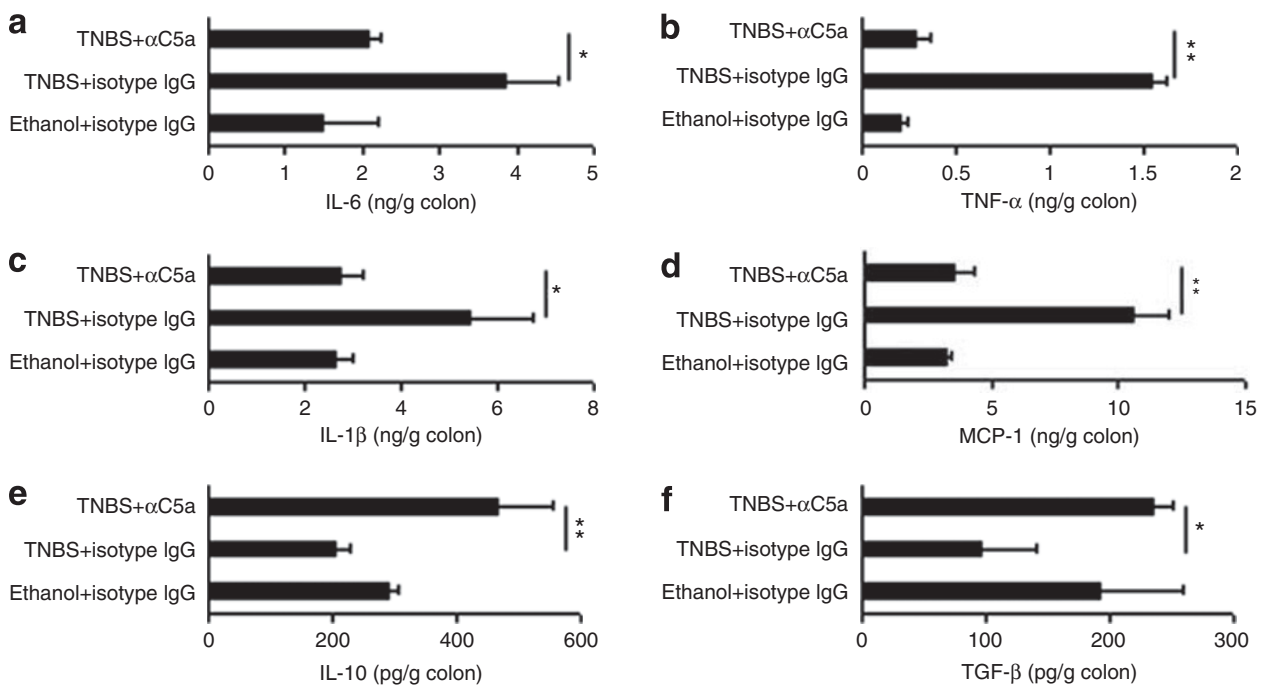

Figure 4 Anti-C5a treatment forms homeostatic cytokine milieu. On day 4 after TNBS or ethanol instillation, the colons from different groups were isolated and homogenated. IL-6 (a), TNF- $\alpha$ (b), IL-1 $\beta$ (c), MCP-1 (d), IL-10 (e), and TGF- $\beta$ (f) production in the supernatants of colonic homogenates was examined. Data are shown as mean \pm s.d. $\left(n=5-8\right.$ mice per group). ${ }^{*} P<0.05 ;{ }^{*} P<0.01$.

production, pieces of colons from anti-C5a-treated mice and controls were homogenated and a variety of colitis-associated cytokine production was assessed. Significant decreased amounts of IL-6 (Figure 4a), TNF- $\alpha$ (Figure $4 \mathrm{~b}$ ), IL- $1 \beta$ (Figure 4c), and MCP-1 (Figure 4d) were found in the colons of mice treated with anti-C5a. Meanwhile, blocking C5a bioactivity dramatically augmented the colonic production of anti-inflammatory cytokines IL-10 (Figure 4e) and TGF- $\beta$ (Figure 4f). In addition, we examined the levels of these proinflammatory mediators in the colons from anti-C5a or prednisolone. Anti-C5a treatment on on-going disease diminished the production of these colitis-related factors, which coincided with less weight loss after anti-C5a therapy, whereas prednisolone had no effects (Supplementary Figure 3B).

\section{Blockade of C5a Activity Restrains Infiltration of Polymorphonuclear Cells into Intestinal Tissues}

It is known that complement $\mathrm{C} 5 \mathrm{a}$ is a potent chemoattractant for recruiting immune cells, such as neutrophil and macrophage, into the sites of inflammation. ${ }^{35,36}$ Thus, whether blocking C5a affects the recruitment of neutrophil/macrophages into inflamed colons, thereby dampens inflammatory responses was addressed. Because complement activation represents an early event during TNBS colitis as described above, colon tissues from anti-C5a-treated and control mice were isolated at $4 \mathrm{~h}, 24 \mathrm{~h}$, and 4 days after colitis induction and neutrophil/macrophage infiltrates were examined. Numerous neutrophils $\left(\mathrm{Gr}-1^{+}\right)$in intestinal mucosa were seen at $4 \mathrm{~h}$ following TNBS instillation (Figure 5a). In contrast, anti-C5a blockade apparently diminished neutrophil infiltrates into colons, comparable to that of controls challenged rectally by ethanol (Figure 5a). Similar results were obtained $24 \mathrm{~h}$ after colitis induction (Figure $5 \mathrm{~b}$ ). When samples isolated at 4 days after TNBS instillation were examined, infiltration of neutrophils was not found in TNBS-instilled mice (Figure 5c), indicating that neutrophil had a role in the early course of colitis development. Consistent with the histological data, MPO contents in the colons from anti-C5a-treated mice were much lower than that from isotype-treated colitis mice at $4 \mathrm{~h}$, following TNBS challenge (Figure 5d). These data indicate that blocking C5a reduces the number of neutrophil infiltrates, thereby attenuates intestinal inflammation. Interestingly, despite the presence of enormous inflammatory cell infiltrates, we did not find the signs of invasion of macrophages $\left(\mathrm{F} 4 / 80^{+}\right.$cells $)$ into the sites of intestinal inflammation at $4 \mathrm{~h}$ (Figure 5a), $24 \mathrm{~h}$ (Figure $5 \mathrm{~b}$ ) or 4 days (Figure $5 \mathrm{c}$ ) after colitis induction.

\section{Blockade of C5a Avtivity Inhibits Th1/Th17 Responses and Elicits Th2 Deviation}

It is widely held that intestinal inflammation induced by TNBS in BALB/c strain is driven by the proinflammatory cytokine IL-12, which promotes the development of pathogenic Th1 $\mathrm{CD}^{+}{ }^{+}$effector cells. ${ }^{3}$ Furthermore, Th17 cells, a novel helper T-cell lineage with characteristics of secreting IL-17, recently have been identified to participate in the pathogenesis of CD and TNBS colitis. ${ }^{37,38}$ To address whether blocking C5a contributes to downregulating Th1/Th17 responses, lymphocytes of mesenteric lymph nodes from different groups at 4 days after TNBS instillation were isolated and stimulated with anti-CD3/anti-CD28. We found that the induction of colitis apparently augmented Th1/Th17 responses (Figure 6a), characterized by secreting large amounts of IFN $-\gamma$ and IL-17, respectively. When blocking C5a activity, this robust Th1/Th17 polarization was suppressed significantly (Figures $6 \mathrm{a}$ and $\mathrm{b}$ ), whereas enhancing Th2 response by producing 
IL-4 (Figure 6b). Furthermore, to define immune response in sites of inflammation, LPMCs were isolated and CD4 ${ }^{+}$ $\mathrm{T}$ cells were sorted. We found that $\mathrm{CD} 4^{+} \mathrm{T}$ cells from colons of TNBS-instilled mice secreted large amounts of IFN- $\gamma$ and IL-17 (Figure 6c). Anti-C5a treatment resulted in significant decrease of these two cytokine productions by $\mathrm{CD} 4^{+} \mathrm{T}$ cells (Figure 6c). We also detected the contents of these cytokines in the attacked tissues. The colons from anti-C5a-treated mice contained less amounts of IL-12, IFN- $\gamma$, IL-17, and more IL-4 contents (Figure 6d). These data revealed clearly that anti-C5a treatment led to the generation of innocuous Th2 bias by inhibiting harmful Th1/Th17 responses.

\section{DISCUSSION}

The representation of components of complement system during the course of mucosal damage has been described in several previous studies, ${ }^{39-42}$ but it is still limited. In the present study, we provide evidence that complement a
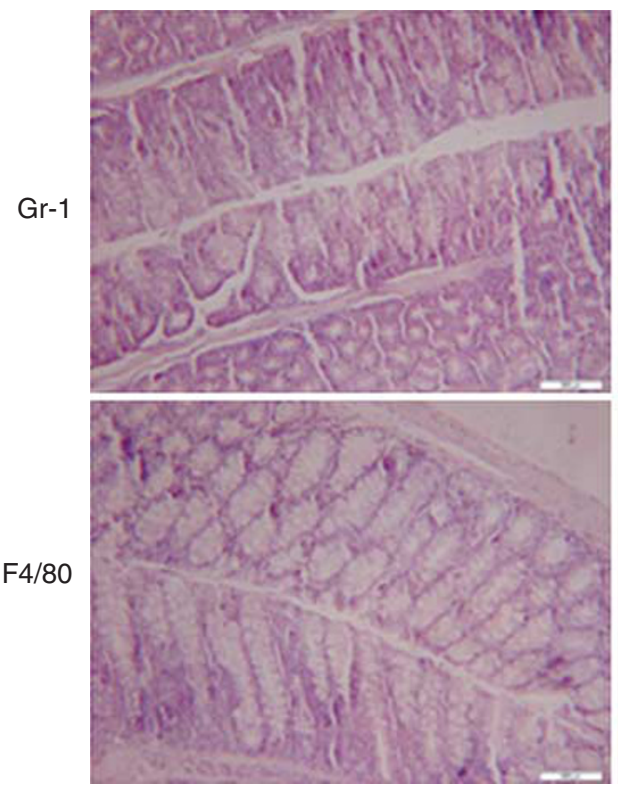

b
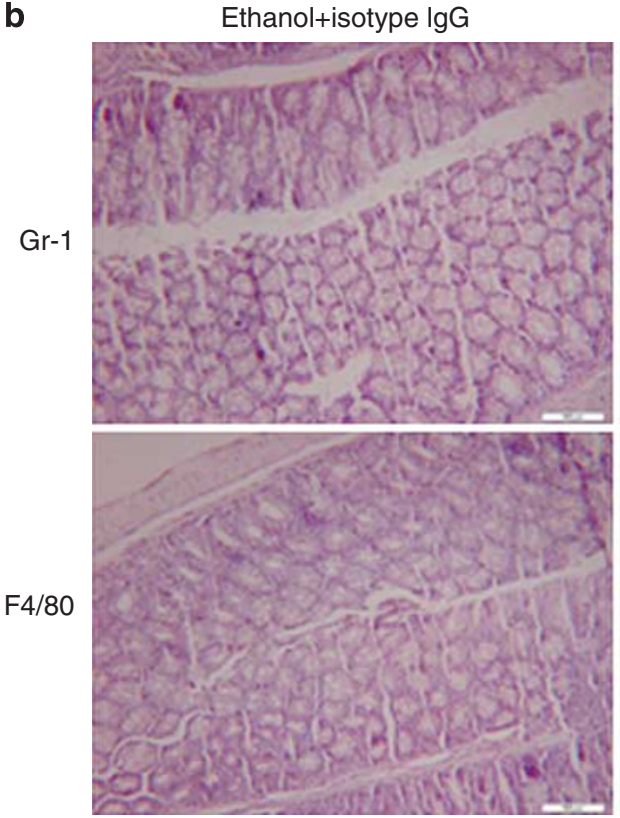

TNBS+isotype lgG
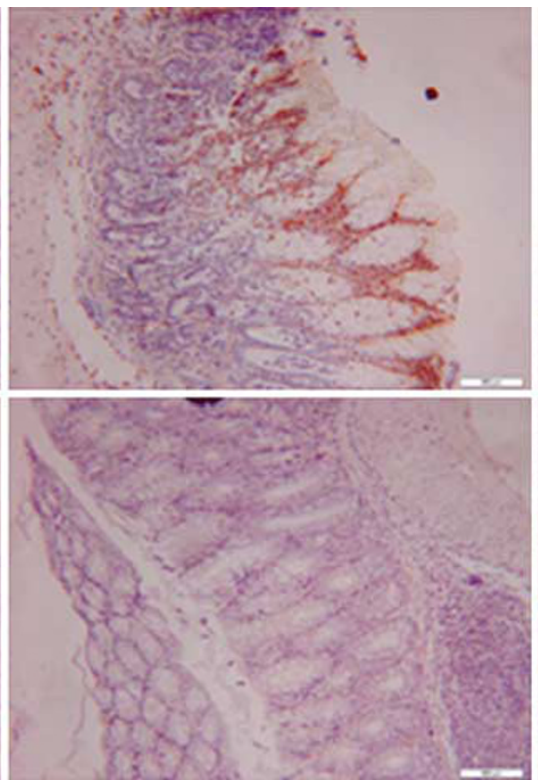

TNBS+isotype $\lg G$
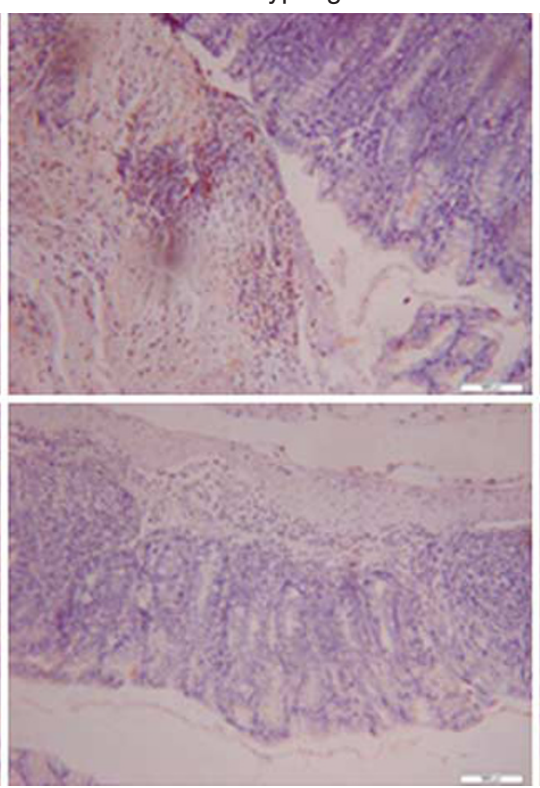

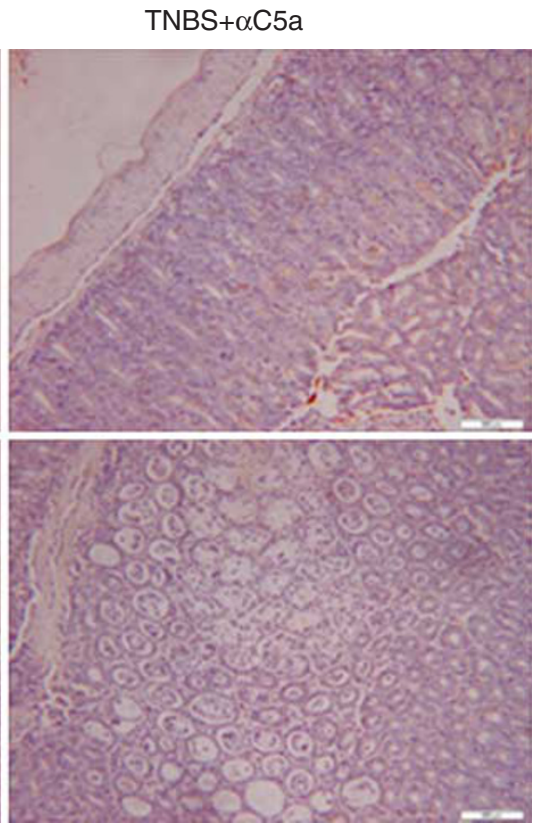

TNBS $+\alpha \mathrm{C} 5 \mathrm{a}$
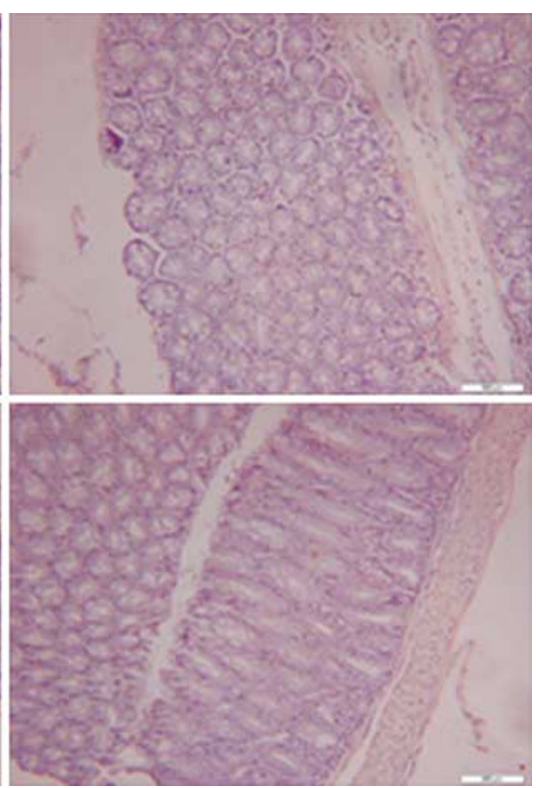

Figure 5 Anti-C5a treatment decreased the infiltration of neutrophils into the colons. Hematoxylin and eosin staining of the colonic tissues from different groups at $4 \mathrm{~h}(\mathbf{a}), 24 \mathrm{~h}(\mathbf{b})$, and 4 days (c) after colitis induction. Magnification: $\times 200$. (d) Levels of MPO in the colons of mice from different groups were measured at $4 \mathrm{~h}$ after colitis induction ( $n=6-8$ mice per group). ${ }^{* *} P<0.01$. 
c

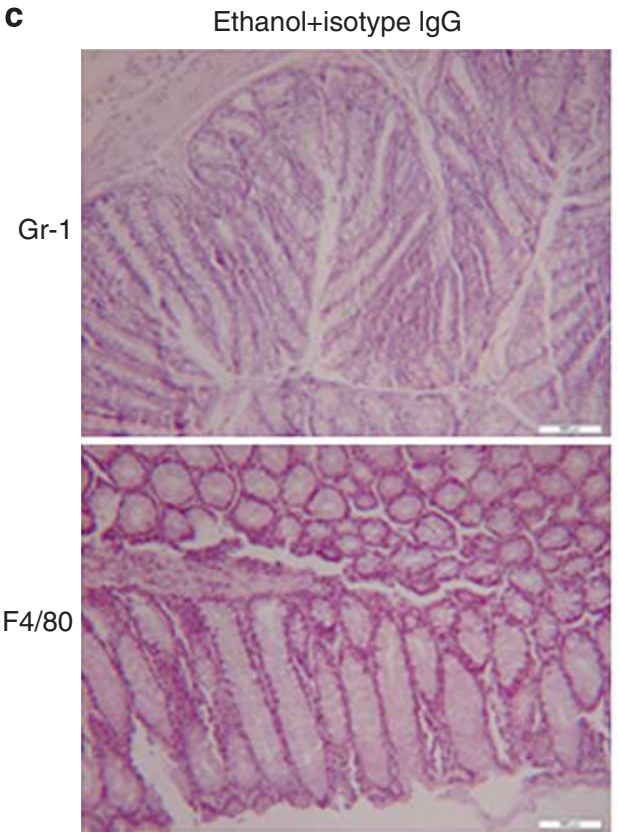

TNBS+isotype $\lg G$

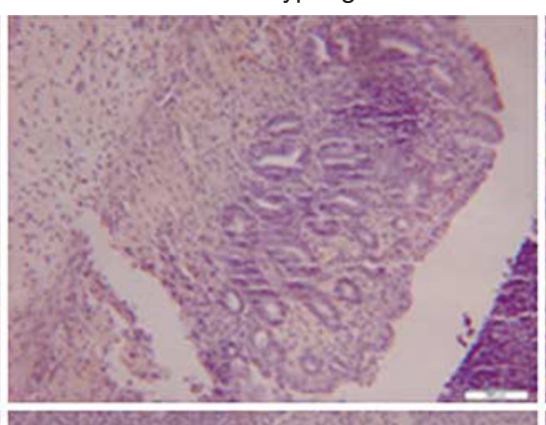

TNBS $+\alpha C 5 a$
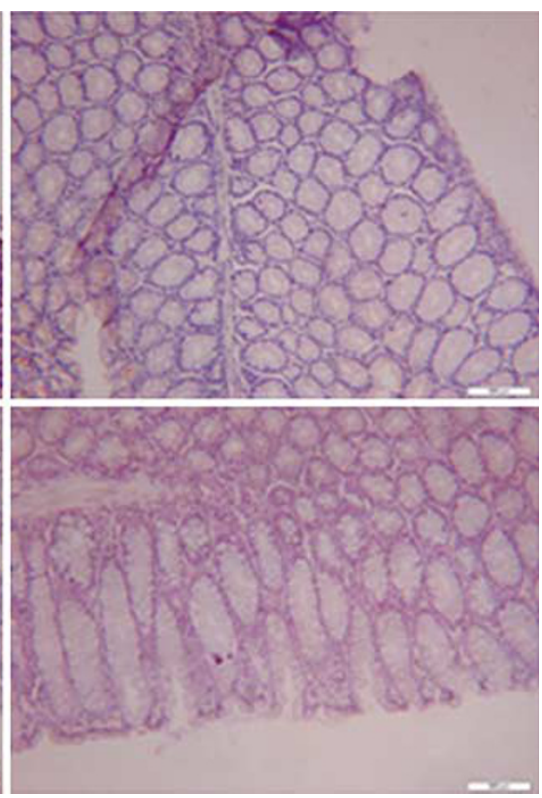

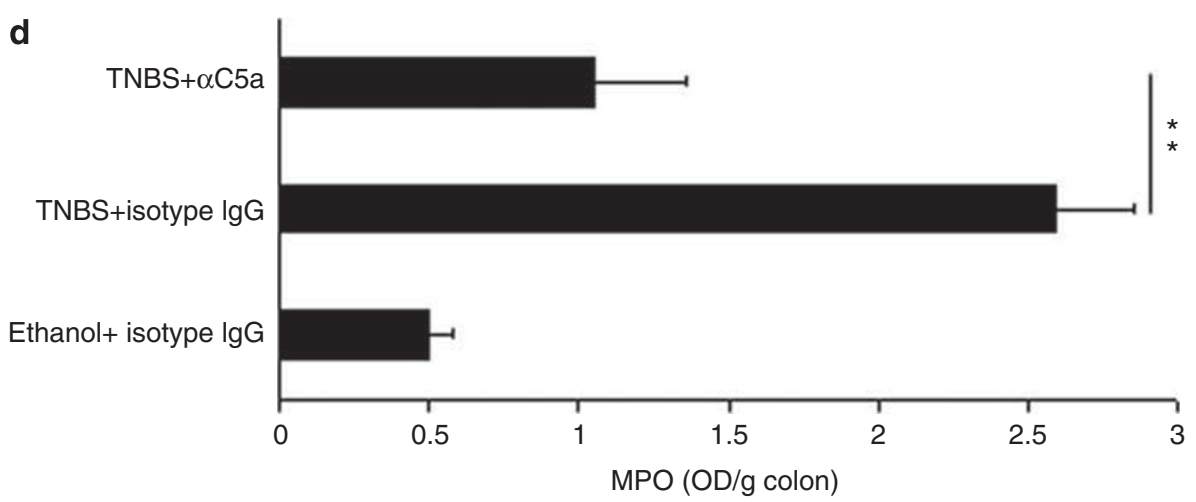

Figure 5 Continued.

activation occurred during the initiation of colitis and at the effector phase. Systemic and local complement activation was found and local activation of complement is more lasting and intensive in TNBS colitis, indicating the intensity of complement activation reflects strong or weak inflammatory responses. The contribution of complement activation to colitis was also confirmed in another experimental model, dextran sulfate sodium (DSS)-induced colitis, showing that milder disease symptoms, less histological damage, and a lower expression of inflammatory mediators were observed in C5aR-deficient C57Bl/6 mice after DSS administration. ${ }^{43}$ Although this study further demonstrated a disease-protective role of $\mathrm{C} 5 \mathrm{a} / \mathrm{C} 5 \mathrm{aR}$ signaling in chronic DSS colitis, our study showed a significant increased production of complement products in affected tissues of UC and CD patients, suggesting that inhibition of complement activation represents a potential regimen for the treatment of IBD.

Complement $\mathrm{C} 5 \mathrm{a}$, as terminal products of complement activation, is a potent chemoattractant for many immune cells, including neutrophil, macrophage, and dendritic cells (DC), which recruits them into the sites of inflammation and results in a cascade of release of inflammatory mediators that ultimately leads to tissue damage. Thus, targeting C5a or $\mathrm{C} 5 \mathrm{aR}$ is becoming the potential means to treat inflammatory diseases involving complement activation. ${ }^{44}$ Woodruff $e t ~ a l^{45}$ obtained a human C5a receptor antagonist, which exhibited to be effective in a number of complement-related diseases, including IBD. However, to our knowledge, its application in the clinic is restrained, probably because of the toxicity, and is relatively compromised. Therefore, new kinds of agents targeting C5a are needed. Here, we identified the efficacy of antibodies to $\mathrm{C} 5 \mathrm{a}$ on preventing from developing colitis. More importantly, the effectiveness of neutralizing anti-C5a antibody on treating on-going disease suggests its therapeutic potentials to IBD in the clinic. It is noteworthy that high level of C5a in sites of inflammation was seen at the early stage of colitis and its level declined to the baseline at the later stage as shown in Figures $1 \mathrm{~b}$ and $2 \mathrm{~g}$. These results indicate that 
a

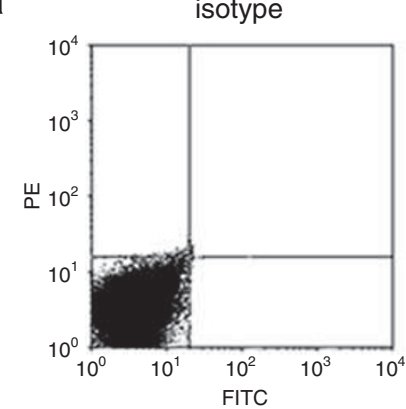

b

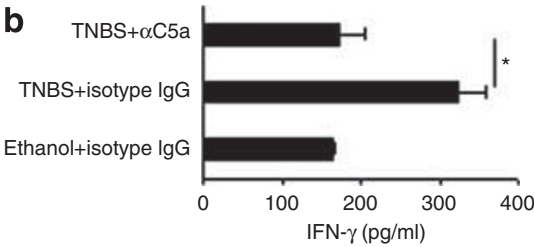

C
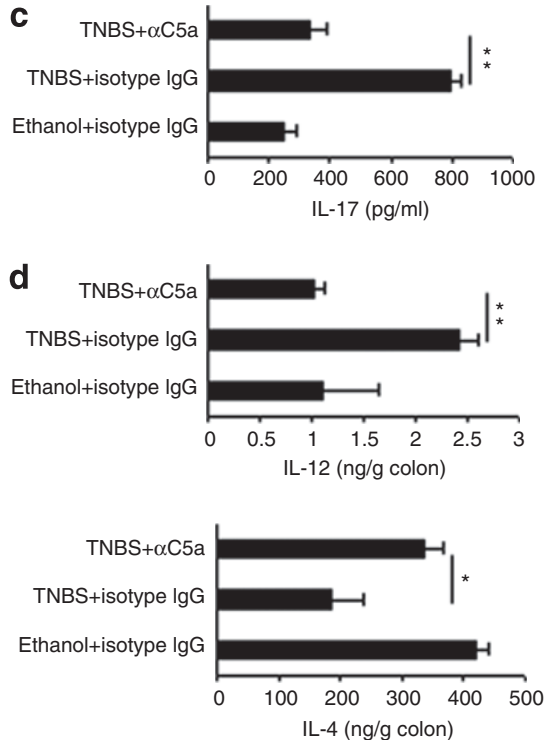

Ethanol+isotype lgG
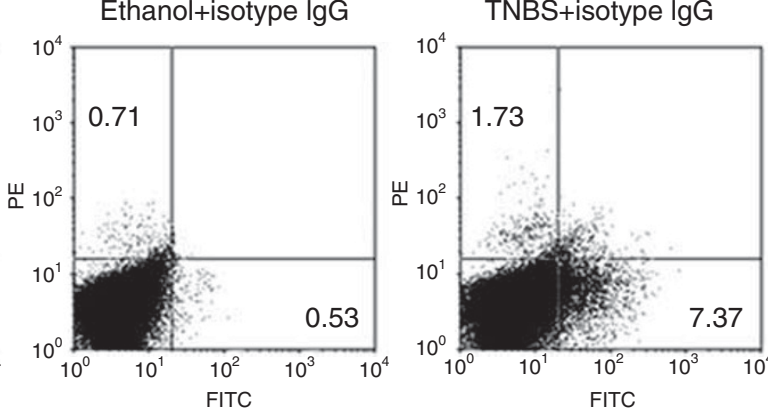

TNBS $+\alpha C 5 a$

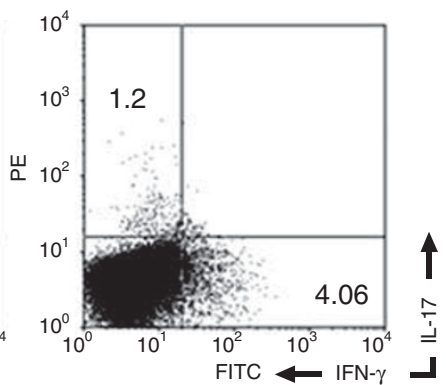

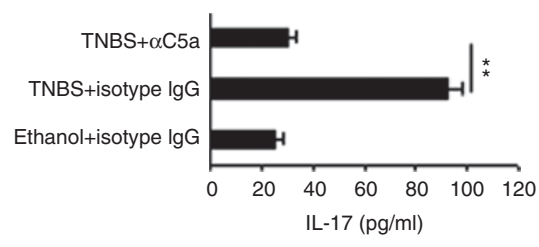
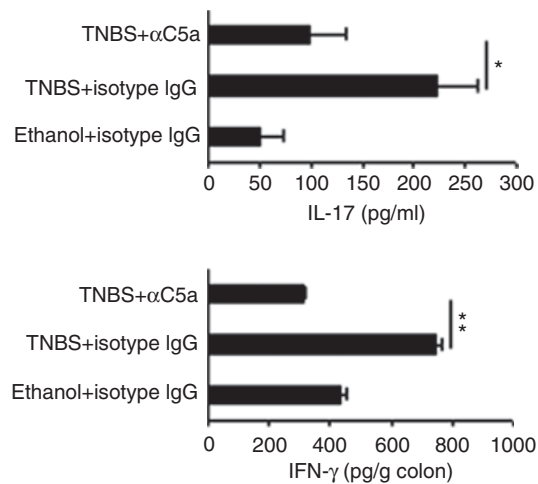
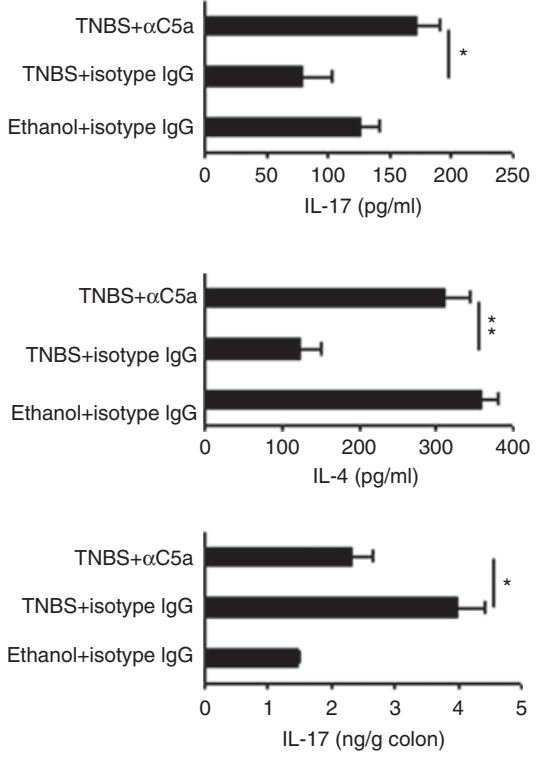

Figure 6 Blocking C5a favors the recovery of Th1/Th17/Th2 immune balance in the colonic tissues. At 4 days after colitis induction, lymphocytes from mesenteric LN of different groups were isolated and incubated with anti-CD3/anti-CD28 for 3 days. The intracellular expression of IFN- $\gamma$ and IL-17 was detected by flow cytometry. The plots are representatives of four independent experiments with similar results (a). The production of IFN- $\gamma$, IL-17, and

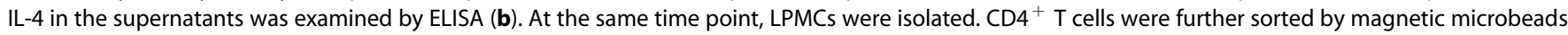
and stimulated with the cocktail of anti-CD3/anti-CD28 for 3 days. The production of IFN- $\gamma$, IL-17, and IL-4 in the supernatants was examined by ELISA (c). At 4 days after TNBS instillation, the colons from different groups were homogenated. IL-12, IFN- $\gamma$, IL-17, and IL-4 production in the supernatants was examined (d). Data are shown as mean \pm s.d. ( $n=6-8$ mice per group). ${ }^{\star} P<0.05 ;{ }^{* *} P<0.01$.

anti-C5a therapy should be performed at the early phase. In addition, the efficacy of anti-C5a on DSS colitis was being evaluated. Anti-C5a showed similar therapeutic effects to that on TNBS colitis (unpublished observation). Notably, sustained high-level production of C3a in colons of TNBSinstilled mice and IBD patients allows us to postulate that treatment of antibody targeting C3a may be beneficial for blocking the development of colitis. Currently, this point is being evaluated in animal models of TNBS and DSS colitis. Consequently, anti-C3a exhibited therapeutic potentials at a certain extent (unpublished observation). Although both
C3a and C5a are well-known anaphylatoxins, activity of C5a is much stronger than C3a. ${ }^{10,46}$ Thus, when applied to treat IBD, anti-C5a may be used before C3a antibody.

When the mechanisms responsible for the efficacy of antiC5a antibody on experimental colitis are to be investigated, we focused on its influence on inflammatory cytokine and chemokine release. Neutralizing C5a by antibody, indeed, reduced the production of numerous mediators in the targeted tissues, such as TNF- $\alpha$. TNF- $\alpha$ is widely held as a key pathogenic factor for colitis pathogenesis in the clinic and experimental models. ${ }^{47-49}$ Its decreased expression 
accounts for the therapeutic effects of anti-C5a. Strikingly, our results showed that anti-C5a treatment led to upregulation of IL-10 and TGF- $\beta$ production in colons, indicating that the efficacy of anti-C5a therapy is also ascribed to enhanced immunomodulatory function of IL-10 and TGF- $\beta$. The details in this process need further investigation.

In view of the potent capacity of C5a to recruit innate immune cells to the sites of inflammation, we investigated whether blocking C5a affects the immigration of immune cells into affected tissues. As a result, large amounts of neutrophils emerged in the colons with inflammation following the colitis induction and blockade of C5a activity significantly limited the entry of these cells into the target tissues. This is another reason that accounts for the therapeutic effects of anti-C5a, considering the fact that histopathological features of IBD lesions include the presence of a significant number of neutrophils within the lamina propria and the crypts, where they form microabscesses. ${ }^{6}$ Anti-C5a treatment prevents from infiltration of neutrophils in the colon, thereby avoids the emergence of a series of events, including oxidative burst, phagocytosis, and inflammatory mediator release and so on. But the details need to further elucidation. Additionally, although macrophages have been shown to have a role in the pathogenesis of IBD in human and animals, ${ }^{50,51}$ we did not observe an obvious infiltration of these cells during TNBS colitis. The reason for this difference is unclear, but may represent a unique population of macrophages residing in the intestine, which negatively express some markers. ${ }^{52}$

As the TNBS colitis model has been reported to be mediated by Th1 and/or Th17 cytokines, we further detected the change of Th1/Th17-specific cytokine expression after blocking C5a. TNBS administration elicited Th1/Th17 immune response in the intestinal tissues and blockade of C5a activity rendered the failure of this process. The data in this study suggest that increased C5a has the ability to push naive $\mathrm{T}$ cells differentiate into Th1/Th17 effector cells, although inhibiting Th2 deviation. This concept is supported by our previous study that C5a could prompt DC to produce IL-23 and Th17 differentiation-related cytokines when binding to C5aR. ${ }^{27}$ These modulated DC had the ability to differentiate naïve $\mathrm{T}$ cells into Th17 cells in vitro. Thus, similar effects of $\mathrm{C} 5 \mathrm{a}$ on antigen-presenting cells in vivo during TNBS colitis are plausible. In addition, C5a may directly function on $\mathrm{T}$ cells, given that activated $\mathrm{T}$ cells are reported to express C5aR in a recent study. ${ }^{53}$ Overall, the therapeutic effects of anti-C5a are attributable to downregulation of pathogenic Th1/Th17 responses and the generation of Th2 bias.

In summary, this study demonstrated a significant role for the complement activation product, $\mathrm{C} 5 \mathrm{a}$, in the pathogenesis of TNBS-induced colitis in human and mice. These findings should encourage the development of anti-complementbased therapies for human IBD. The potent therapeutic effects of the polyclonal anti-C5a antibody supports a possible role for the use of monoclonal antibody specific for human C5a in the treatment of IBD in humans.
Supplementary Information accompanies the paper on the Laboratory Investigation website (http://www.laboratoryinvestigation.org)

\section{ACKNOWLEDGEMENT}

This work was supported by the grants from the National Key Basic Research Program of China (2007CB512406; 2009CB522408) and the National Natural Science Foundation of China (30801029).

\section{DISCLOSURE/CONFLICT OF INTEREST}

The authors declare no conflict of interest.

1. Fiorucci C. Inflammatory bowel disease: etiology and pathogenesis. Gastroenterology 1998;115:182-205.

2. Elson CO, Sartor RB, Tennyson GS, et al. Experimental models of inflammatory bowel disease. Gastroenterology 1995;109:1344-1367.

3. Strober W, Fuss IJ, Blumberg RS. The immunology of mucosal models of inflammation. Annu Rev Immunol 2002;20:495-549.

4. McGovern D, Powrie F. The IL-23 axis plays a key role in the pathogenesis of IBD. Gut 2007;56:1333-1336.

5. Hue $\mathrm{S}$, Ahern $\mathrm{P}$, Buonocore $\mathrm{S}$, et al. Interleukin-23 drives innate and $\mathrm{T}$ cell-mediated intestinal inflammation. J Exp Med 2006;203:2473-2483.

6. Xavier RJ, Podolsky DK. Unravelling the pathogenesis of inflammatory bowel disease. Nature 2007:448:427-434.

7. Fiorucci $S$, Mencarelli $A$, Palazzetti $B$, et al. Importance of innate immunity and collagen binding integrin $\alpha 1 \beta 1$ in TNBS-induced colitis. Immunity 2002;17:769-780.

8. Cario E, Podolsky DK. Differential alteration in intestinal epithelial cell expression of toll-like receptor 3 (TLR3) and TLR4 in inflammatory bowel disease. Infect Immun 2000;68:7010-7017.

9. Nenci A, Becker C, Wullaert A, et al. Epithelial NEMO links innate immunity to chronic intestinal inflammation. Nature 2007;446:557-561.

10. Guo RF, Ward PA. Role of C5a in inflammatory responses. Annu Rev Immunol 2005;23:821-852.

11. Robbins RA, Russ WD, Rasmussen JK, et al. Activation of the complement system in the adult respiratory distress syndrome. Am Rev Respir Dis 1987;135:651-658.

12. Linton SM, Morgan BP. Complement activation and inhibition in experimental models of arthritis. Mol Immunol 1999;36:905-914.

13. Welch TR. Complement in glomerulonephritis. Nat Genet 2002;31: 333-334.

14. Ffrench-Constant C. Pathogenesis of multiple sclerosis. Lancet 1994; 343:271-275

15. Arumugam TV, Shiel IA, Woodruff TM, et al. The role of the complement system in ischemia-reperfusion injury. Shock 2004;21:401-409.

16. Hawlisch $\mathrm{H}$, Wills-karp $\mathrm{M}$, Karp $\mathrm{CL}$, et al. The anaphylatoxins bridge innate and adaptive immune responses in allergic asthma. Mol Immunol 2004;41:123-131.

17. Marder SR, Chenoweth $\mathrm{DE}$, Goldstein IM, et al. Chemotactic responses of human peripheral blood monocytes to the complement-derived peptides C5a and C5a des Arg. J Immunol 1985;134:3325-3331.

18. Riedemann NC, Guo RF, Sarma VJ, et al. Expression and function of the C5a receptor in rat alveolar epithelial cells. J Immunol 2002;168: 1919-1925.

19. Laudes IJ, Chu JC, Huber-Lang M, et al. Expression and function of C5a receptor in mouse microvascular endothelial cells. J Immunol 2002;169:5962-5970.

20. Werfel T, Oppermann $M$, Schulze $M$, et al. Binding of fluoresceinlabeled anaphylatoxin C5a to human peripheral blood, spleen, and bone marrow leukocytes. Blood 1992;79:152-160.

21. Haviland DL, McCoy RL, Whitehead WT, et al. Cellular expression of the $\mathrm{C} 5 \mathrm{a}$ anaphylatoxin receptor ( $\mathrm{C} 5 \mathrm{aR})$ : demonstration of $\mathrm{C} 5 \mathrm{Ar}$ on nonmyeloid cells of the liver and lung. J Immunol 1995;154:1861-1869.

22. Schieferdecker HL, Schlaf G, Jungermann $\mathrm{K}$, et al. Functions of anaphylatoxin $\mathrm{C5} a$ in rat liver: direct and indirect actions on nonparenchymal and parenchymal cells. Int Immunopharmacol 2001;1:469-481.

23. Kolios G, Petoumenos C, Nakos A. Mediators of inflammation: production and implication in inflammatory bowel disease. Hepatogastroenterology 1998;45:1601-1609.

24. Laufer J, Katz Y, Passwell JH. Extrahepatic synthesis of complement proteins in inflammation. Mol Immunol 2001;38:221-229. 
25. Nieuwenhuis EE, Neurath MF, Corazza N, et al. Disruption of T helper 2 immune responses in Epstein-Barr virus-induced gene 3-deficient mice. Proc Natl Acad Sci USA 2002;99:16951-16956.

26. Neurath MF, Weigmann B, Finotto $S$, et al. The transcription factor T-bet regulates mucosal $T$ cell activation in experimental colitis and Crohn's disease. J Exp Med 2002;195:1129-1143.

27. Xu R, Wang R, Han G, et al. Complement C5a regulates interleukine-17 by affecting the crosstalk between DCs and $\gamma \delta$ T cells in CLP-induced sepsis. Eur J Immunol 2010;40:1079-1088.

28. Van der Heijden PJ, Stok W. Improved procedure for the isolation of functionally active lymphoid cells from the murine intestine. J Immunol Methods 1987;103:161-167.

29. Krawisz JE, Sharon P, Stenson WF. Quantitative assay for acute intestinal inflammation based on myeloperoxidase activity. Assessment of inflammation in rat and hamster models. Gastroenterology 1984;87: 1344-1350.

30. Bock D, Martin U, Gärtner $S$, et al. The $C$ terminus of the human $C 5 a$ receptor (CD88) is required for normal ligand-dependent receptor internalization. Eur J Immunol 1997;27:1522-1529.

31. Pushparaj PN, Tay HK, Wang CC, et al. VAMP8 is essential in anaphylatoxin-induced degranulation, TNF- $\alpha$ secretion, peritonitis, and systemic inflammation. J Immunol 2009;183:1413-1418.

32. Issuree PD, Pushparaj PN, Pervaiz S, et al. Resveratrol attenuates C5a-induced inflammatory responses in vitro and in vivo by inhibiting phospholipase D and sphingosine kinase activities. FASEB J 2009;23: 2412-2424.

33. Guo RF, Riedemann NC, Bernacki KD, et al. Neutrophil C5a receptor and the outcome in a rat model of sepsis. FASEB $J$ 2003;13: 1889-1891.

34. Morgan BP. Mechanisms of tissue damage by the membrane attack complex of complement. Complement Inflamm 1989;6:104-111.

35. Struyf $S$, Gouwy $M$, Dillen $C$, et al. Chemokines synergize in the recruitment of circulating neutrophils into inflamed tissue. Eur Immunol 2005;35:1583-1591.

36. Distelmaier K, Adlbrecht C, Jakowitsch J, et al. Local complement activation triggers neutrophil recruitment to the site of thrombus formation in acute myocardial infarction. Thromb Haemost 2009;102: 564-572.

37. Alex $\mathrm{P}, \mathrm{Zachos} \mathrm{NC}$, Nguyen $\mathrm{T}$, et al. Distinct cytokine patterns identified from multiplex profiles of murine DSS and TNBS-induced colitis. Inflamm Bowel Dis 2009;15:341-352.

38. Daniel C, Sartory NA, Zahn N, et al. Immune modulatory treatment of trinitrobenzene sulfonic acid colitis with calcitriol is associated with a change of a T helper (Th) 1/Th17 to a Th2 and regulatory T cell profile. J Pharmacol Exp Ther 2008;324:23-33.
39. Ahrenstedt O, Knutson L, Nilsson B, et al. Enhanced local production of complement components in the small intestines of patients with Crohn's disease. N Eng J Med 1990;322:1345-1349.

40. Berstad AE, Brandzaeg P. Expression of cell membrane complement regulatory glycoproteins along the normal and diseased human gastrointestinal tract. Gut 1998;42:522-529.

41. Berstad $A E$, Brandzaeg $P$, Stave $R$, et al. Epithelium related deposition of activated complement in Helicobacter pylori-associated gastritis. Gut 1997;40:196-203.

42. Andoh A, Kinoshita K, Rosenberg I, et al. Intestinal trefoil factor induces decay-accelerating factor expression and enhances the protective activities against complement activation in intestinal epithelial cells. J Immunol 2001;167:3887-3893.

43. Johswich $\mathrm{K}$, Martin $\mathrm{M}$, Bleich $\mathrm{A}$, et al. Role of the $\mathrm{C} 5 \mathrm{a}$ receptor (C5aR) in acute and chronic dextran sulfate-induced models of inflammatory bowel disease. Inflamm Bowel Dis 2009:15:1812-1823.

44. Ricklin D, Lambris JD. Complement-targeted therapeutics. Nat Biotechnol 2007:25:1265-1275.

45. Woodruff TM, Arumugam TV, Shiels IA, et al. A potent human C5a receptor antagonist protects against disease pathology in a rat model of inflammatory bowel disease. J Immunol 2003;171:5514-5520.

46. Walport MJ. Complement. First of two parts. N Engl J Med 2001;344: 1058-1066.

47. Murch SH, Lamkin VA, Savage MO, et al. Serum concentrations of tumor necrosis factor alpha in childhood chronic inflammatory bowel disease. Gut 1991;32:913-917.

48. Murch SH, Braegger CP, Walker-Smith JA, et al. Location of tumo necrosis factor alpha by immunohistochemistry in chronic inflammatory bowel disease. Gut 1993;34:1705-1709.

49. Kojouharoff $G$, Hans W, Obermeier $F$, et al. Neutralization of tumor necrosis factor (TNF) but not of IL-1 reduces inflammation in chronic dextran sulphate sodium-induced colitis in mice. Clin Exp Immunol 1997:107:353-358.

50. Schenk M, Bouchon A, Seibold F, et al. TREM-1-expressing intestinal macrophages crucially amplify chronic inflammation in experimental colitis and inflammatory bowel diseases. J Clin Invest 2007;117:3097-3106.

51. Kamada N, Hisamatsu $T$, Okamoto $\mathrm{S}$, et al. Unique $\mathrm{CD} 14^{+}$intestinal macrophages contribute to the pathogenesis of Crohn's disease via IL23/IFN- $\gamma$ axis. J Clin Invest 2008;118:2269-2280.

52. Smith PD, Ochsenbauer-Jambor C, Smythies LE. Intestinal macrophages: unique effector cells of the innate immune system. Immunol Rev 2005; 206:149-159.

53. Strainic MG, Liu J, Huang D, et al. Locally produced complement fragments $\mathrm{C} 5 \mathrm{a}$ and $\mathrm{C} 3 \mathrm{a}$ provide both costimulatory and survival signals to naïve $\mathrm{CD}^{+} \mathrm{T}$ cells. Immunity $2008 ; 28: 425-435$. 